\title{
Return-based classification of absolute return funds
}

\author{
April 30, 2014
}

Philipp Gerlach

Finance Department, Goethe University

Grueneburgplatz 1 (Uni-PF. H 23)

Frankfurt am Main, Germany

E-Mail: gerlach@finance.uni-frankfurt.de

\author{
Raimond Maurer \\ Finance Department, Goethe University \\ Grueneburgplatz 1 (Uni-PF. H 23) \\ Frankfurt am Main, Germany \\ E-Mail: maurer@finance.uni-frankfurt.de
}

The authors are grateful for research support provided by the German Investment and Asset Management Association (BVI). Opinions and errors are solely those of the authors and not of the institutions with whom the authors are affiliated. (C) 2013 Gerlach and Maurer. 


\title{
Return-based classification of absolute return funds
}

\author{
Philipp Gerlach Raimond Maurer
}

\begin{abstract}
We apply a return-based classification approach on a sample of absolute return funds registered for sale in Europe. The classification process results in eight groups with specific risk and return profiles. We describe each group by two dimensions of an underlying investment style: asset allocation and trading strategy. While the returns of one group are largely determined by the asset allocation, the returns of the other seven groups are driven by different trading strategies. Our estimated classification explains $20 \%$ of the in-sample and $13 \%$ of the out-of-sample cross-sectional return variation, which is superior to existing approaches.
\end{abstract}

JEL Classification: G23

Keywords: Absolute Return Funds, Return-Based Classification, Style Analysis 


\section{Introduction}

The mutual fund industry steadily introduces new types of products to the market; absolute return funds are such products. The purpose of absolute return funds is - similar to hedge funds - to deliver stable returns above the money market level, irrespective of market conditions. In contrast to hedge funds, absolute return funds are distributed as Undertakings for Collective Investment in Transferable Securities (UCITS) in the European mutual funds market and therefore are subject to stricter legal requirements. Complying with the stricter UCITS regulation comes for the benefit of a simplified permission for sale in the European Economic Area, in particular to private investors. ${ }^{1}$

The first absolute return funds entered the market by the end of 2002 as a reaction to the market downturns in the previous years. Investors sought for investment products that do not expose them to the downside risk of the stock market while offering the possibility of a higher return than the money market. The market for absolute return funds registered for sale in Europe increased from 140 funds with $€ 0.03$ billion of assets under management in January 2003 to 2,019 funds with $€ 92.68$ billion of assets under management by end of July 2012. The growth of absolute return funds was elevated notably by the revised regulation of UCITS in 2004, allowing UCITS to invest in a wider range of financial securities and derivatives. ${ }^{2}$ Since July 2011 investment companies are required to provide a Key Investor Information Document (KIID) for each UCITS. ${ }^{3}$ Besides information about the objective, investment policy, fees, past performance, and practical issues, the KIID shall disclose possible rewards and risks associated with the particular fund. The European Securities and Markets Authority (ESMA) provides detailed guidance how to estimate and present the risks of the particular fund depending on a self-classification by the investment company to one out of five categories: Market funds, absolute return funds, total return funds, life cycle funds, or structured funds. The fact that regulation considers absolute return funds as a separate category with a specific reward and risk profile reflects the relevance of this product in the UCITS universe.

Although absolute return funds share a common return target, we observe enormous differences in their historical returns. Using a sample of 542 absolute returns funds registered for sale in Europe with a return series from August 2007 to July 2012, we find that the average of the pairwise correlations of their returns is only 0.3 , and in $17 \%$ of the cases the

\footnotetext{
${ }^{1}$ See Directive 85/611/EEC, Directive 2007/16/EC, and Directive 2009/65/EC

${ }^{2}$ See Directive 2007/16/EC

${ }^{3}$ See Directive 2009/65/EC
} 
pairwise correlations is even zero or lower. ${ }^{4}$ The heterogeneity in the correlations indicates that the category of absolute return funds consists of several potentially different investment approaches. This raises the question in how many different reward and risk subcategories the universe of absolute return funds should be classified, which is the focus of our paper.

The literature concerned with absolute return funds is focused on performance measurement. Waring and Siegel (2006) emphasize that the term "absolute return" is misleading. Even though the systematic factor betas of absolute return funds may be rather implicit and more complex, as compared to classical funds with market indices benchmarks, absolute return funds are, in fact, relative-return products which should be benchmarked against the fund specific set of factor betas. Lochmüller (2008) studies the historical returns of a sample of absolute return funds registered for sale in Germany for 2005-2008. During this period, most absolute return fund managers were able to generate positive annualized returns. Yet only half of the funds show a positive Sharpe Ratio. Clifford (2014) analyses a sample of US absolute return funds for the period 2003-2010. Using the Fama-French four factor model and the seven-factor model by Fung and Hsieh (1997), he finds no evidence of positive alpha. Clifford (2014) also compares absolute return funds with equity funds and shows that they have higher expenses and turnover ratios, are smaller in size, and their returns are less volatile. In addition, absolute return funds hold a significant portion of non-cash assets. Yet this literature is silent on the heterogeneity of investment styles of absolute returns funds, which is important for regulators, rating agencies of mutual funds, and private investors.

The literature on classification of mutual funds shows two approaches (Gruber (2001)). In the first approach, the number and characteristics of the groups are prespecified. Typically these characteristics are based on portfolio holdings (e.g. stocks, bonds, balanced) and/or selfreported investment objectives (e.g. growth, value). Thereafter, each fund is assigned to one group, often in conjunction by using linear factor models. Brown and Goetzmann (1997) emphasize that this approach is not appropriate for classifying mutual funds which employ dynamic trading strategies and mutual funds that make use of derivatives. As in the case of hedge funds this is also true for absolute return funds. Therefore, in the second approach, the number and characteristics of the groups are endogenously derived from the historical mutual funds returns. These endogenous, return-based classification approaches are most suited for explorative classification studies since they do not require any prior knowledge about the latent structure underlying the mutual funds.

\footnotetext{
${ }^{4}$ Datasource: Lipper, a Thomson Reuters Company
} 
We apply the well-known endogenous, return-based classification approach introduced by Brown and Goetzmann (1997) on a sample of absolute return funds registered for sale in Europe. We find that absolute return funds are to be classified into eight distinct groups. The return distributions of the estimated groups range from low risk, normal distributed returns to asymmetric return distributions with high tail risks. Following Fung and Hsieh (1997), we characterize each group by two dimensions of an underlying investment style: asset allocation and trading strategy.

We estimate the asset allocation of each group using the approach by Sharpe (1992) based on indices representing different stock, bond, and money markets. A high explanatory power of the estimated asset allocation indicates that the investment style explicitly or implicitly is passive while a low explanatory power indicates an active investment style. Our analysis shows substantial differences of the asset allocation characteristics and their explanatory power among the various groups. Only for one group the return series is primarily determined by the asset allocation component. For five groups the asset allocation plays a medium role and for two groups it is almost unimportant. Thus, the returns of these groups are also driven by active management, in particular a specific trading strategy.

To estimate the underlying trading strategy we sort the realized returns of each index into three states: downturn, trendless, and uptrend. Next, we relate the realized returns of the various groups to the corresponding state of each index. We find that some groups produce non-linear, option-like payoff profiles, but with low exposure. Our classification of absolute return funds is distinct from existing classification approaches and is better able to explain the cross-sectional variation of fund returns.

\section{Methodology and Data}

\subsection{Generalized Style Classification}

We apply the generalized style classification (GSC) procedure introduced by Brown and Goetzmann (1997). The GSC approach finds a natural grouping for funds by estimating the time series of within-group mean returns such that the resulting sum-of-squares is minimized and then corrects the least squares estimates to account for time-varying and fund-specific residual return variances. Brown and Goetzmann $(1997,2003)$ show that the GSC is better able to explain the cross-sectional variation of fund returns than other return-based classification approaches. 


\section{Underlying Return Model}

Brown and Goetzmann (1997) decompose the return of a fund into a part that is common among a group of funds following the same investment style and a part that is fund specific.

$$
r_{i, t}=\mu_{k, t}+e_{i, t}
$$

where

$$
\begin{aligned}
r_{i, t} & =\text { return of fund } i \text { in period } t \\
\mu_{k, t} & =\text { return of style group } k \text { in period } t \\
e_{i, t} & =\text { specific return of fund } i \text { in period } t
\end{aligned}
$$

Brown and Goetzmann (1997) state, if the fund specific part has a zero mean and is uncorrelated across funds, the classification into groups of different investment styles will suffice to explain the cross-sectional variation of fund returns.

\section{K-Means Clustering}

In a first step we apply k-means clustering to estimate the return time series of a specified number of groups. ${ }^{5,6}$ This iterative relocation approach minimizes the within-group sum-ofsquares by moving funds from one group to another.

$$
\begin{aligned}
\operatorname{SSQ}(K) & =\sum_{t=1}^{T} \sum_{k=1}^{K} \sum_{\substack{i=1 \\
i \in k}}^{I}\left(r_{i, t}-\hat{\mu}_{k, t}\right)^{2} \rightarrow \min ! \\
\hat{\mu}_{k, t} & =\frac{1}{\operatorname{count}(i \in k)} \sum_{\substack{i=1 \\
i \in k}}^{I} r_{i, t}
\end{aligned}
$$

where

$$
\operatorname{SSQ}(K)=\text { sum-of-squares within } K \text {-groups }
$$

\section{Adjustment of Estimated Means and Sum of Squares}

In a second step we follow Brown and Goetzmann (1997) and adjust the estimated return time series of the style groups and the resulting within-group sum-of-squares to reduce the influence of funds that strongly vary around the within-group mean return and dates with a high within-group return variation on the means and the sum-of-squares.

\footnotetext{
${ }^{5}$ A detailed description of the applied GSC approach can be found in the appendix.

${ }^{6}$ See Steinley (2006) for an extensive summary of the k-means clustering technique.
} 


$$
\begin{gathered}
\hat{\mu}_{k, t}^{*}=\sum_{\substack{i=1 \\
i \in k}}^{I} \frac{r_{i, t}}{\operatorname{var}\left(\hat{e}_{i}\right)} / \sum_{\substack{i=1 \\
i \in k}}^{I} \frac{1}{\operatorname{var}\left(\hat{e}_{i}\right)} \\
\operatorname{SSQ}^{*}(K)=\sum_{t=1}^{T} \sum_{k=1}^{K} \sum_{\substack{i=1 \\
i \in k}}^{I} \frac{\left(r_{i, t}-\hat{\mu}_{k, t}^{*}\right)^{2}}{\operatorname{var}\left(\hat{e}_{i}^{*}\right) \operatorname{var}\left(\hat{e}_{t}^{*}\right)}
\end{gathered}
$$

\section{Determine Number of Groups}

To determine the optimal number of groups we follow Brown and Goetzmann (1997) and use a likelihood ratio test by Quandt (1960). We run a series of GSC procedures for an increasing number of $K=1, \ldots, 10$ groups. For each pair of consecutive GSC solutions we derive the test statistic.

$$
L R_{K, K+1}=T \times I\left(\ln \frac{S S Q^{*}(K)}{T \times I}-\ln \frac{S S Q^{*}(K+1)}{T \times I}\right)
$$

This test statistic should have an approximate chi-squared distribution with $2 T$ degrees of freedom.

\subsection{Absolute Return Funds Data}

We classify a sample of absolute return funds registered for sale in Europe. The fund data is obtained from Lipper, a Thomson Reuters Company. Lipper selects absolute return funds based on the fund name or the stated objective. In order to partition this broad category into more homogeneous sub-categories, Lipper classifies absolute return funds depending on the reference currency and on a rolling value at risk estimate. Additionally, Lipper assigns each fund to one asset type according to its primary investment objective as stated by the promoter and according to fund documentations. Funds investing in income markets with an average maturity of more than one year are assigned to bond, funds investing in stock markets to equity, funds with a strategic mix of variable income and fixed income securities to mixed assets, funds investing in fixed income markets with an average maturity less than a year to money market, and funds investing in derivatives, warrants, structured products, unclassified or undisclosed assets, hedge funds or commodities to other. ${ }^{7}$

Our sample includes all primary share classes listed in the Lipper database as an absolute return fund, registered for sale in Europe, and having a series of monthly returns from January 2009 to December 2011.

\footnotetext{
${ }^{7}$ Lipper (2012)
} 
[Insert table 1 here]

Table 1 presents the asset types and reference currencies of the sample as reported by Lipper. Most absolute return funds report their returns in Euro (84\%), followed by the British pound or pence sterling $(7 \%)$, and US dollars $(6 \%)$; A minor part uses the Swiss franc $(2 \%)$ or Swedish krona (1\%). Most of the funds invest in mixed assets $(61 \%)$, followed by bonds (19\%), other (9\%), equity (7\%), and money market (4\%).

\section{Results}

\subsection{Summary of the GSC Process}

Based on the likelihood ratio test suggested by Quandt (1960) we classify the sample of absolute return funds into eight groups.

[Insert table 2 here]

Table 2 presents technical coefficients resulting from a series of k-means clustering procedures with an increasing numbers of groups. The likelihood ratios and the corresponding p-values are used to determine the number of groups into which the sample of absolute return funds should be classified. The likelihood ratio should have an approximate chi-squared distribution with $2 T$ degrees of freedom. We see that the likelihood ratios drop under the critical value of $102.81(\alpha=0.01)$ when increasing the number of groups from eight to nine. This is also reflected in the p-values. For a number of one to seven groups the p-values are close to zero indicating that an increase in the number of groups is useful in explaining returns. ${ }^{8}$ The table also shows the variation explained by each clustering solution, measured by $\eta_{K}^{2}=1-\frac{S S Q^{*}(K)}{S S Q^{*}(1)}$. The determined clustering solution with eight groups explains $28 \%$ of the total variation.

\subsection{Characteristics of GSC Groups}

\subsubsection{Return Distribution Characteristics}

[Insert table 3 here]

Table 3 presents the characteristics of the return time-series of the eight GSC groups. Each group exhibits a specific risk and return profile as can be seen from the four central moments in combination with the pairwise correlation coefficients. Even if the correlation coefficients indicate that some groups are similar, their central moments differ. Table 3 shows three key

\footnotetext{
${ }^{8}$ Brown and Goetzmann (1997)
} 
issues we want to point out. Looking first at the pairwise correlations we see that groups $\mathrm{V}$ and VII are negatively correlated to almost all other groups. However, they are also distinct from each other as indicated by the low correlation coefficient. This becomes even more evident when we look at the central moments of their return time-series. While group V has a high mean return and volatility, group VII is characterized by a zero mean return but with positive return-jumps reflected by the positive kurtosis. Looking again at the pairwise correlations we see that group VIII has high correlation coefficients to groups I, III, IV, and VI suggesting that group VIII is similar to these groups. However, the high correlations are misleading. Besides differences in the mean returns and standard deviations, group VIII incorporates a high downside risk reflected in the negative skewness and high kurtosis. Finally looking at the central moments we see that groups I and IV are different to the others since their standard deviations are high compared to the standard deviations of the other groups.

\subsubsection{Underlying Investment Styles}

To give the estimated GSC groups an economic interpretation we analyze the underlying investment styles. In a first step we analyze if differences in the location decisions are reflected in the estimated GSC groups. We follow the concept of Sharpe (1992) and create a mimicking portfolio of broad market indices for every absolute return fund. To account for currency risks the indices returns are expressed in the reference currency of the fund. We use three stock market, three bond market, one commodity, and four money market indices. The stock market indices are: MSCI Europe, MSCI USA, and MSCI Emerging Markets. The bond market indices are: Barclays Euro-Aggregate, Barclays-US Aggregate, and Barclays Global Emerging Markets. The commodity index is: Rogers International Commodity. The money market indices are: J.P. Morgan Euro Cash 1 Month, J.P. Morgan UK Cash 1 Month, J.P. Morgan Switzerland Cash 1 Month, and J.P. Morgan US Cash 1 Month. The market indices data is obtained from Thomson Reuters Datastream.

\section{[Insert table 4 here]}

Table 4 presents the within-group averages of the mimicking portfolio weights and their explanatory power. If the variance of fund returns can be explained by the variance of the mimicking portfolio, the fund performance is largely driven by the asset allocation and not by an active management. We see that the explanatory power $R^{2}$ varies between the groups. Groups II and VII have a low $R^{2}$, indicating that the return series are driven by active management and not by the asset location. Groups III-VI and VIII have a medium $R^{2}$. Half of 
their return variation can be explained by the asset allocation. Group I has a high $R^{2}$. Twothird of the return variation can be explained by the location decision. The mimicking portfolios of groups II-VIII primarily consist of Euro money market instruments and Euro denominated bonds. The mimicking portfolio of group $\mathrm{I}$, the group with the highest $\mathrm{R}^{2}$, primarily consists of European stocks, Euro and UK money market instruments.

In a second step we estimate the underlying trading strategies of the funds within the GSC groups. Following the Fung and Hsieh (1997), we relate the return series of the GSC groups to the development of different market indices.

For each index we sort the index and GSC group returns in ascending order with respect to the index returns and equally divide them into three states titled downturn, trendless, and uptrend.

[Insert table 5 here]

Table 5 presents the mean returns of the indices and the resulting GSC groups in each state. We see that the GSC groups exhibit individual state depended payoff profiles.

Looking at the returns depending on the development of stock markets in panel A, we see that the returns of GSC groups I-IV, and VIII are positive linearly related to the returns of stock markets while groups V-VII produce non-linear, option like payoff profiles. The return profile of group $\mathrm{V}$ is comparable to a long put on the European stock market, a long straddle on to the US stock market, and a short straddle on emerging markets. Group VI shows a return profile that is characteristic for portfolio insurance strategies. Funds in this group limit the downside risk while participating on positive stock market movements. Group VII exhibits a return profile similar to a short position on stock markets. It has positive returns in downtrends, returns close to zero in trendless markets, and negative returns in uptrends. Looking at the returns depending on the development of bond markets in panel B we see GSC groups III and V are positive linearly related to bond market returns. Group VIII is negative, linearly related to Euro and USD bond markets but positive to emerging markets. The GSC groups I, II, IV, VI and VII mainly show return profiles similar to straddles. Lastly looking at the returns depending on the development of the commodity market in panel $\mathrm{C}$ we that GSC groups III, VI and VIII are positive linearly related. GSC group VII is negative linearly related. Groups II and IV have return profiles similar to long straddles and group V a profile similar to a short call.

\subsubsection{Comparison with Asset Class and Lipper Classification Schemes}

We analyze a potential relationship between the asset type of absolute return funds and their membership to the estimated GSC groups. 
[Insert table 6 here]

Table 6 presents the cross-tabulation of the asset types of the funds and their membership to the GSC groups. We see that table 6 exhibits no structural pattern. The asset types are distributed among all GSC groups.

We also analyze a potential relationship between the Lipper classification and the estimated GSC. Lipper seeks to create homogeneous groups through classifying absolute return funds depending on the reference currency and an estimated value at risk level.

[Insert table 7 here]

Table 7 presents the cross-tabulation of the Lipper classification and the GSC. Overall, we do not see any congruence between the two classification solutions. First, we look at the fund currencies as one aspect of the classification by Lipper and the membership to the GSC groups. We see that $83 \%$ of the funds with non-Euro reference currency are assigned to GSC groups I, IV, and V However, funds with Euro reference currency are distributed among all GSC groups. Then, we look on the value at risk levels in the GSC groups. We see that no group contains only funds of one value at risk level. Interestingly, each of the GSC groups II, IV, VII, and VIII contain equal proportions of all three value at risk levels.

\subsubsection{Explanatory Power}

We estimate the ability of the GSC to explain the cross-sectional return variance and compare the explanatory power with the asset type and Lipper classification.

First, we test the ability of the different classification approaches to explain the cross sectional variation of the realized fund returns. For every month for the period January 2009 December 2011, we regress the cross section of fund returns against the asset type classification, the Lipper classification, and the GSC. The asset type and Lipper classifications are both as reported by Lipper in August 2012. The GSC is estimated for the period January 2009 - December 2011.

Then, we test the ability of the GSC approach to explain the variation of future fund returns. We estimate the GSC groups using 36 months of return data and then regress the cross section of fund returns of the subsequent month against the GSC solution. This is done for seven rolling windows. ${ }^{9}$

[Insert table 8 here]

\footnotetext{
${ }^{9}$ We allow funds to move in and out of the sample.
} 
Table 8 presents the average adjusted $\mathrm{R}^{2}$ resulting from regressing the cross-sectional monthly fund returns against the alternative classifications. The in-sample results show that the GSC has the highest explanatory power followed by the Lipper classification and then by the asset type classification. On average, the estimated GSC explains $20 \%$ of the cross-sectional fund return variation, the Lipper classification $12 \%$ and the asset type classification $5 \%$. The outof-sample results show that the average explanatory power of the GSC decreases to $13 \%$.

\section{Conclusion}

Even though absolute return funds pursue a common return target, there is enormous variation in their historical return series. We apply a return-based classification approach by Brown and Goetzmann (1997) to estimate the classification that best reflects the central differences in the return profiles of absolute return funds registered for sale in Europe. For each subgroup of our classification we estimate the investment style in terms of the asset allocation and the trading strategy.

We find a classification of eight subgroups best reflects the differences in the return profiles of absolute return funds. The specific return profiles range from low risk, normal distributed returns to asymmetric return distributions with high tail risks. One group of absolute return funds exhibits a style primarily defined by the location decision, not by an active management. These funds show a strong exposure to European stocks, Euro and UK money market instruments. Five groups exhibit a style almost equally defined by the asset location and an active management. Two groups exhibit a style almost exclusively defined by an active management. Contrasting our return-based style solution to the classification reported by Lipper, a leading rating company for mutual funds, we find that our approach is better able to explain the cross-sectional variation in returns.

The results of our study have several implications for investors, regulators, and rating companies for mutual funds. It needs more thoughtfulness for investors to select an adequate absolute return fund, because several investment approaches with alternative return profiles are offered to investors. Rating companies can support investors in their process of selecting and evaluating absolute return funds through implementing a finer, return-based classification which reflects the different investment styles and the resulting return profiles. Finally, regulators should be aware that entire groups of absolute funds exhibit return profiles far away from the promised cash plus return benchmark. This raises the question if more specific requirements for funds are necessary to label themselves as an absolute return fund. 


\section{References}

Brown, S. J. and W. N. Goetzmann (1997): Mutual fund styles. Journal of Financial Economics 43 (3), 373-399.

Brown, S. J. and W. N. Goetzmann, (2003): Hedge Funds with Style. Journal of Portfolio Management 29 (2), 101-112.

Clifford, C., B. Jordan, and T. Riley (2013): Do Absolute-Return Mutual Funds Have Absolute Returns? Journal Of Investing, 22 (4), 23-40.

European Parliament and European Council: Directive 85/611/EEC of 20 December 1985 on the coordination of laws, regulations and administrative provisions relating to undertakings for collective investment in transferable securities (UCITS). Official Journal of the European Union (L 375/3), 3-18.

European Parliament and European Council: Directive 2007/16/EC of 19 March 2007 implementing Council Directive 85/611/EEC on the coordination of laws, regulations and administrative provisions relating to undertakings for collective investment in transferable securities (UCITS) as regards the clarification of certain definitions. Official Journal of the European Union (L 79), 11-19.

European Parliament and European Council: Directive 2009/65/EC of the European Parliament and of the Council of 13 July 2009 on the coordination of laws, regulations and administrative provisions relating to undertakings for collective investment in transferable securities (UCITS). Official Journal of the European Union (L 302), 32-96.

Fung, W. and D. A. Hsieh (1997): Empirical Characteristics of Dynamic Trading Strategies: The Case of Hedge Funds. The Review of Financial Studies 10 (2), 275-302.

Gruber, M. J. (2001): Identifying the Risk Structure of Mutual Fund Returns. European Financial Management, 7 (2), 147-159.

Lipper (2012): Lipper Global Classification, World Wide Web: http://www.lipperweb.com/docs/Research/Methodology/Lipper_Global_Classifications_Defi nitions2012.pdf (accessed: 26 May 2013)

Lochmüller, R. (2008): Fünf Jahre Absolute-Return-Strategien in Deutschland - eine Qualitätsanalyse. Zeitschrift für das gesamte Kreditwesen 61 (16), 782-784.

Quandt, R. E. (1960): Tests of the Hypothesis that a Linear Regression System Obeys Two Separate Regimes. Journal of the American Statistical Association 55 (290), 324-330. 
Sharpe, W. F. (1992): Asset allocation: Management style and performance measurement. Journal of Portfolio Management 18 (2), 7-19.

Steinley, D. (2006): K-means clustering: A half-century synthesis. British Journal of Mathematical and Statistical Psychology 59 (1), 1-34.

Steinley, D. and M. J. Brusco (2007): Initializing K-means Batch Clustering: A Critical Evaluation of Several Techniques. Journal of Classification 24 (1), 99-121.

Waring, M. B. and L. B. Siegel (2006): The Myth of the Absolute-Return Investor. Financial Analysts Journal 62 (2), 14-21. 


\section{Appendix}

We use the following k-means algorithm to estimate the return time series representative for each of the $k=1, \ldots, K$ groups. We randomly select the return time series of $K$-funds as the potential return time series of the $K$-groups. For all funds we calculate the sum-of-squares to each of the $k=1, \ldots, K$ return time series and assign the funds, all at once, to the group with the smallest sum-of-squares. We recalculate the return time series of each group as the time series of within-group mean returns. We iterate the last two steps of assigning funds to the nearest group and recalculating the time series of each group until a stable partition is reached. Then, we reassign and recalculate the return time-series, fund by fund, until a local minimum is reached. To find a global minimum we follow Steinley and Brusco (2007) and repeat the previous steps 10,000 times, each with random initial return time series, and finally use the solution with the lowest sum-of-squares. To reduce the influence of highly volatile funds on the classification process we follow Brown and Goetzmann (1997) and standardize the fund returns by the inverse of the estimated standard deviation. We adjust the estimated return time series and sum-of-squares of the groups to account for time varying and fund specific residual returns. For each month we calculate the within-group mean returns and the fund residual returns.

$$
\begin{aligned}
& \hat{\mu}_{k, t}=\frac{1}{\operatorname{count}(i \in k)} \sum_{\substack{i=1 \\
i \in k}}^{I} r_{i, t} \\
& \hat{e}_{i, t}=r_{i, t}-\hat{\mu}_{k, t}
\end{aligned}
$$

For all funds we calculate the time-series residual variances $\operatorname{var}\left(\hat{e}_{i}\right)$ and for all months the cross-sectional residual variances $\operatorname{var}\left(\hat{e}_{t}\right)$. We follow Brown and Goetzmann (1997) and normalize the variances by the average marginal variances. We correct the estimated returns of the groups by calculating the weighted within-group mean returns.

$$
\hat{\mu}_{k, t}^{*}=\sum_{\substack{i=1 \\ i \in k}}^{I} \frac{r_{i, t}}{\operatorname{var}\left(\hat{e}_{i}\right)} / \sum_{\substack{i=1 \\ i \in k}}^{I} \frac{1}{\operatorname{var}\left(\hat{e}_{i}\right)}
$$

We recalculate the variances using the weighted means and correct the sum-of-squares for the derived clustering solution. 


$$
S S Q^{*}(K)=\sum_{t=1}^{T} \sum_{k=1}^{K} \sum_{\substack{i=1 \\ i \in k}}^{I} \frac{\left(r_{i, t}-\hat{\mu}_{k, t}^{*}\right)^{2}}{\operatorname{var}\left(\hat{e}_{i}^{*}\right) \operatorname{var}\left(\hat{e}_{t}^{*}\right)}
$$




\section{Table 1}

Underlying asset types and reference currencies of absolute return funds

\begin{tabular}{lrrrrrr}
\hline & \multicolumn{7}{c}{ Reference Currency } \\
& CHF & EUR & GBP & SEK & USD & Total \\
\hline Bond & 1 & 58 & 6 & & 7 & 72 \\
Equity & & 16 & 3 & 3 & 5 & 27 \\
Mixed Assets & 6 & 207 & 14 & 1 & 8 & 236 \\
Money Market & & 14 & & & & 14 \\
Other & & 28 & 5 & & 2 & 35 \\
\hline Total & 7 & 323 & 28 & 4 & 22 & 384 \\
\hline Note: GPB also includes funds with reference currency GBX
\end{tabular}

This table presents the number of funds belonging to a specified reference currency and to one of five asset types in which the absolute return funds claim to invest. The sample includes all primary share classes listed in the Lipper database as an absolute return fund, registered for sale in Europe, with a series of monthly returns from January 2009 to December 2011. The reference currency and the assignment into one of the five asset categories is inputted by Lipper based on the statement of the fund promoter.

\section{Table 2}

\section{Technical summary of alternative generalized style classifications}

\begin{tabular}{cccrr}
\hline $\begin{array}{c}\text { Number of } \\
\text { groups }\end{array}$ & $\begin{array}{c}\text { Adjusted sum-of- } \\
\text { squares }\end{array}$ & Explained variation & Likelihood ratio & p-value \\
\hline 1 & $60,068.07$ & & $1,233.10$ & 0.00 \\
2 & $54,942.02$ & $9 \%$ & $1,211.18$ & 0.00 \\
3 & $50,333.16$ & $16 \%$ & 593.51 & 0.00 \\
4 & $48,217.94$ & $20 \%$ & 882.89 & 0.00 \\
5 & $45,234.70$ & $25 \%$ & 223.94 & 0.00 \\
6 & $44,507.82$ & $26 \%$ & 334.37 & 0.00 \\
7 & $43,444.21$ & $28 \%$ & 145.89 & 0.00 \\
8 & $42,988.14$ & $28 \%$ & 79.03 & 0.27 \\
9 & $42,743.09$ & $29 \%$ & 29.34 & 1.00 \\
10 & $42,652.46$ & $29 \%$ & 42.63 & 1.00 \\
\hline
\end{tabular}

This table presents coefficients that are used to describe the explanatory power of different GSC solutions and to determine the optimal number of groups into which absolute returns should be divided. For multiple runs, each with one additional group, the sum-of-squares is calculated and adjusted for time-varying and fund-specific residual return variance. The adjusted sum of squares is used to calculate the explained variation, measured as the reduction in the sum-of-squares of the classification relative to the unclassified sample. The sums-ofsquares are also used to calculate a likelihood ratio test suggested by Quandt (1960) to determine the optimal number of groups. This test statistic should have an approximate chisquared distribution with $2 T$ degrees of freedom. 
Table 3

Return characteristics of the GSC groups

Panel A: Distribution of the GSC group returns

\begin{tabular}{lrrrrrrrr}
\hline & \multicolumn{8}{c}{ Generalized Style Classification group } \\
& I & \multicolumn{1}{c}{ II } & \multicolumn{1}{c}{ III } & IV & V & VI & VII & VIII \\
\hline Mean & 0.30 & 0.01 & 0.13 & 0.33 & 0.19 & 0.19 & 0.00 & 0.06 \\
Standard deviation & 1.88 & 0.49 & 0.49 & 1.01 & 0.55 & 0.49 & 0.37 & 0.86 \\
Skewness & -0.07 & 0.07 & -0.86 & 0.09 & 0.04 & 0.42 & 0.72 & -1.81 \\
Kurtosis & 2.73 & 2.90 & 3.39 & 2.96 & 3.11 & 3.85 & 3.57 & 8.93 \\
\hline
\end{tabular}

Panel B: Pairwise correlation among GSC groups

\begin{tabular}{lrrrrrrrr}
\hline & \multicolumn{1}{c}{ I } & \multicolumn{1}{c}{ II } & \multicolumn{1}{c}{ III } & IV & V & VI & VII & VIII \\
\hline GSC group I & 1 & & & & & & & \\
GSC group II & 0.47 & 1 & & & & & & \\
GSC group III & 0.79 & 0.53 & 1 & & & & & \\
GSC group IV & 0.81 & 0.59 & 0.78 & 1 & & & & \\
GSC group V & -0.10 & -0.02 & 0.17 & 0.16 & 1 & & & \\
GSC group VI & 0.59 & 0.16 & 0.77 & 0.64 & 0.12 & 1 & \\
GSC group VII & -0.57 & -0.30 & -0.42 & -0.20 & 0.39 & -0.17 & 1 & \\
GSC group VIII & 0.81 & 0.53 & 0.81 & 0.76 & -0.18 & 0.64 & -0.49 & 1 \\
\hline
\end{tabular}

This table presents the four central moments of the GSC groups' return time series and the pairwise correlations between the GSC groups for the period January 2009 to December 2011. The return time series of each group is calculated as the cross-sectional weighted mean returns of the funds belonging to the respective GSC group. 
Table 4

Sharpe style weights of GSC groups

\begin{tabular}{|c|c|c|c|c|c|c|c|c|}
\hline & \multicolumn{8}{|c|}{ Generalized Style Classification group } \\
\hline & 1 & II & III & IV & $\mathrm{V}$ & $\mathrm{VI}$ & VII & VIII \\
\hline \multicolumn{9}{|l|}{ Stocks } \\
\hline Europe & 30.32 & 2.45 & 6.98 & 11.08 & 0.34 & 2.92 & 0.02 & 12.99 \\
\hline USA & 3.64 & 1.52 & 0.00 & 0.63 & 0.06 & 0.00 & 0.33 & 1.35 \\
\hline Emerging Markets & 7.95 & 0.13 & 1.85 & 5.40 & 0.96 & 3.43 & 1.39 & 5.13 \\
\hline \multicolumn{9}{|l|}{ Bonds } \\
\hline Euro & 9.53 & 13.18 & 21.30 & 18.56 & 44.81 & 9.32 & 8.61 & 4.75 \\
\hline USD & 1.38 & 0.00 & 0.04 & 3.61 & 0.68 & 3.61 & 1.56 & 0.15 \\
\hline Emerging Markets & 0.60 & 0.04 & 0.00 & 1.22 & 6.86 & 0.00 & 7.57 & 0.05 \\
\hline Commodities & 3.73 & 6.16 & 2.56 & 8.60 & 1.10 & 1.44 & 4.14 & 3.02 \\
\hline \multicolumn{9}{|l|}{ Money Market } \\
\hline Euro & 25.21 & 73.17 & 63.06 & 27.38 & 30.06 & 66.86 & 58.71 & 63.59 \\
\hline UK & 12.33 & 0.20 & 3.08 & 11.12 & 4.20 & 3.13 & 4.78 & 1.17 \\
\hline Switzerland & 2.86 & 1.59 & 1.12 & 6.27 & 7.59 & 0.06 & 3.94 & 6.59 \\
\hline US & 2.46 & 1.57 & 0.00 & 6.13 & 3.34 & 9.22 & 8.95 & 1.21 \\
\hline $\mathrm{R}^{2}$ & 0.66 & 0.17 & 0.47 & 0.51 & 0.46 & 0.39 & 0.15 & 0.44 \\
\hline
\end{tabular}


Table 5

State dependent return profiles of GSC groups

Panel A: GSC groups' returns depending on the development of stock markets

\begin{tabular}{|c|c|c|c|c|c|c|c|c|c|}
\hline & \multirow[b]{2}{*}{ Market } & \multicolumn{8}{|c|}{ Generalized Style Classification group } \\
\hline & & 1 & II & III & IV & V & VI & VII & VIII \\
\hline \multicolumn{10}{|l|}{ Europe } \\
\hline State 1 & -4.02 & -1.58 & -0.30 & -0.24 & -0.46 & 0.30 & -0.01 & 0.24 & -0.61 \\
\hline State 2 & 0.73 & 0.19 & 0.03 & 0.12 & 0.15 & 0.15 & 0.07 & -0.05 & 0.00 \\
\hline State 3 & 6.27 & 2.30 & 0.30 & 0.52 & 1.28 & 0.13 & 0.51 & -0.18 & 0.78 \\
\hline \multicolumn{10}{|l|}{ USA } \\
\hline State 1 & -4.93 & -1.59 & -0.37 & -0.20 & -0.42 & 0.43 & -0.01 & 0.24 & -0.63 \\
\hline State 2 & 1.68 & 0.28 & 0.15 & 0.11 & 0.29 & 0.02 & 0.12 & -0.06 & 0.08 \\
\hline State 3 & 7.06 & 2.22 & 0.24 & 0.49 & 1.10 & 0.13 & 0.47 & -0.18 & 0.72 \\
\hline \multicolumn{10}{|c|}{ Emerging Markets } \\
\hline State 1 & -5.65 & -1.58 & -0.37 & -0.32 & -0.58 & 0.17 & -0.07 & 0.25 & -0.66 \\
\hline State 2 & 0.57 & 0.39 & 0.18 & 0.25 & 0.58 & 0.28 & 0.17 & -0.08 & 0.16 \\
\hline State 3 & 10.57 & 2.10 & 0.22 & 0.48 & 0.98 & 0.12 & 0.47 & -0.17 & 0.67 \\
\hline \multicolumn{10}{|c|}{ Panel B: GSC groups' returns depending on the development of bond markets } \\
\hline & & \multicolumn{8}{|c|}{ Generalized Style Classification group } \\
\hline & Market & I & II & III & IV & V & $\mathrm{VI}$ & VII & VIII \\
\hline \multicolumn{10}{|l|}{ Euro } \\
\hline State 1 & -0.81 & 0.28 & -0.04 & 0.02 & 0.07 & -0.39 & 0.13 & -0.12 & 0.17 \\
\hline State 2 & 0.42 & 0.38 & 0.17 & 0.17 & 0.52 & 0.27 & 0.13 & 0.01 & 0.12 \\
\hline State 3 & 1.42 & 0.25 & -0.10 & 0.22 & 0.39 & 0.69 & 0.31 & 0.11 & -0.12 \\
\hline \multicolumn{10}{|l|}{ USD } \\
\hline State 1 & -0.38 & 0.27 & 0.07 & 0.07 & 0.11 & -0.35 & 0.20 & -0.09 & 0.26 \\
\hline State 2 & 0.66 & 0.60 & 0.00 & 0.12 & 0.55 & 0.32 & 0.26 & 0.05 & 0.11 \\
\hline State 3 & 1.37 & 0.04 & -0.04 & 0.21 & 0.31 & 0.60 & 0.13 & 0.04 & -0.20 \\
\hline \multicolumn{10}{|c|}{ Emerging Markets } \\
\hline State 1 & -0.95 & -0.89 & -0.14 & -0.29 & -0.41 & -0.04 & -0.13 & 0.06 & -0.49 \\
\hline State 2 & 1.41 & 0.24 & 0.10 & 0.21 & 0.34 & 0.27 & 0.12 & -0.08 & 0.09 \\
\hline State 3 & 3.65 & 1.57 & 0.07 & 0.48 & 1.05 & 0.35 & 0.59 & 0.02 & 0.56 \\
\hline
\end{tabular}


Panel C: GSC groups' returns depending on the development of commodity market

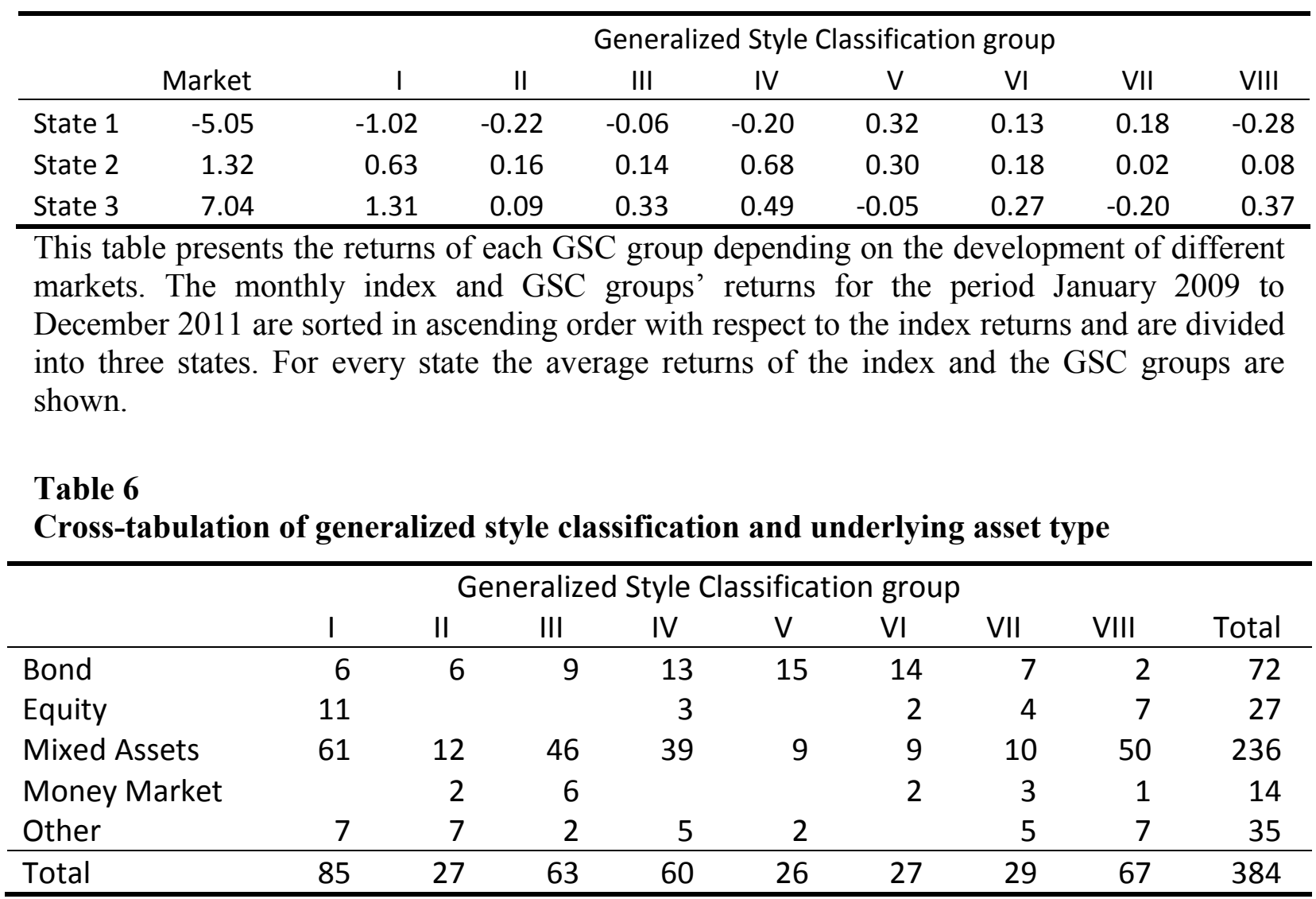

This table shows the underlying asset type of the funds belonging to one of the eight GSC groups. The information about the underlying type of assets is provided by Lipper. Lipper assigns each fund to one asset type according to the primary investment objective, as stated by the promoter, and to fund documents' information. 
Table 7

Cross-tabulation of generalized style classification and Lipper classification

\begin{tabular}{|c|c|c|c|c|c|c|c|c|c|}
\hline \multicolumn{10}{|c|}{ Generalized Style Classification group } \\
\hline & 1 & II & III & IV & V & $\mathrm{VI}$ & VII & VIII & Total \\
\hline $\mathrm{CHF}$ & 3 & & & 1 & 1 & & & 2 & 7 \\
\hline EUR Low & 4 & 9 & 41 & 8 & 12 & 18 & 9 & 16 & 117 \\
\hline EUR Medium & 13 & 8 & 16 & 20 & 8 & 4 & 7 & 22 & 98 \\
\hline EUR High & 38 & 8 & 1 & 16 & 2 & 1 & 10 & 23 & 99 \\
\hline GBP Low & & & 1 & 2 & 1 & & 1 & & 5 \\
\hline GBP Medium & 5 & & & 4 & & & & & 9 \\
\hline GBP High & 11 & 1 & & 1 & & & & & 13 \\
\hline USD Low & 1 & & & 3 & 1 & 3 & 1 & & 9 \\
\hline USD Medium & 3 & & & 2 & 1 & & & & 6 \\
\hline USD High & 3 & & & & & & & & 3 \\
\hline Other & 4 & 1 & 4 & 3 & & 1 & 1 & 4 & 18 \\
\hline Total & 85 & 27 & 63 & 60 & 26 & 27 & 29 & 67 & 384 \\
\hline
\end{tabular}

This table contrasts the Lipper classification which bases on the funds' reference currency and on a rolling value at risk estimation with the GSC classification based on the realized fund returns.

\section{Table 8}

\section{Cross-sectional variance explained by different classification schemes}

\begin{tabular}{cccc}
\hline & & Adjusted $\mathrm{R}^{2}$ & \\
& Asset Type & Lipper & GSC \\
\hline In-sample & 0.0495 & 0.1245 & 0.2008 \\
& $(0.0415)$ & $(0.0820)$ & $(0.1093)$ \\
Out-of-sample & & & 0.1274 \\
& & & $(0.0711)$ \\
\hline
\end{tabular}

This table presents the average adjusted $\mathrm{R}^{2}$ from regressing the cross sectional fund returns against alternative classification systems. Standard deviations are reported in parentheses. Asset type classifies funds into five groups based on the type of assets the funds primarily invests in. Lipper classification sorts funds into 11 groups depending on the reference currency and an estimated three year value at risk. Generalized style classification allots funds into eight groups according to an adjusted k-means clustering technique such that the variation of returns in all groups is minimized. In-sample shows the results from regressing the monthly, cross-sectional returns for January 2009 to December 2011 against the asset type and Lipper classification, both reported by Lipper August 2012, and against the GSC as estimated for January 2009 to December 2011. Out-of-sample shows the results from regressing the GSC for a 3 year estimation interval against the subsequent one-month crosssection of returns. The out-of-sample regression is performed for seven iterations. 